\title{
Hot forming of shape memory alloys in steel shells: formability, interface, bonding quality
}

\author{
Gregory Gerstein ${ }^{1}$. Christoph Kahra ${ }^{1}$ - Oleksandr Golovko ${ }^{1}$ - Florian Schäfke ${ }^{1} \cdot$ Christian Klose $^{1}$. \\ Sebastian Herbst ${ }^{1} \cdot$ Florian Nürnberger $^{1} \cdot$ Hans Jürgen Maier ${ }^{1}$
}

Received: 30 July 2020 / Accepted: 25 January 2021 / Published online: 10 February 2021

(C) The Author(s) 2021

\begin{abstract}
Metal forming of shape memory alloys (SMA) can be challenging since these are very often brittle due to their intermetallic character. However, formability is often needed not only for realising the desired geometry but also for tailoring the microstructure and the functional properties. To investigate whether the encapsulation in a steel shell can improve the formability of shape memory alloys, $\mathrm{Co}_{49} \mathrm{Ni}_{21} \mathrm{Ga}_{30}$ and $\mathrm{Ni}_{49.5} \mathrm{Fe}_{14.5} \mathrm{Mn}_{4.0} \mathrm{Ga}_{26.0} \mathrm{Co}_{6.0}$ samples were subjected to tensile tests, upsetting, rolling and extrusion. A ferritic steel (1.0503) was used as the shell material. The shell was employed to curtail the formation of tensile stresses in the core, to maintain high temperatures during processing and to prevent oxidation. With this approach, not only forming of the SMA in the steel shell was possible but also an intensive metallurgical bond between the SMA and the steel shell can be achieved during hot rolling or extrusion.
\end{abstract}

Keywords SMA $\cdot$ Hot deformation $\cdot$ Steel shell $\cdot$ Metallurgical bonding $\cdot$ Extrusion $\cdot$ Rolling $\cdot$ Upsetting $\cdot$ Hot tensile tests

\section{Introduction}

Shape memory alloys (SMA) feature the phenomenon of returning to their original shape when sufficient heat is provided subsequent to a deformation. The one-way or two-way shape memory effects are based on the activation of martensitic transformations. In the case of the one-way effect, a deformation is required to form martensite. In general, martensite is either formed during cooling or by deformations. Upon subsequent heating, martensite reverts to its original austenitic phase state and its original shape. With the two-way shape memory effect, the alloy takes different shapes when heated and cooled. SMA can also feature the phenomenon of superelasticity, in which the atomic bonds between atoms in an austenitic state are stretched to a limit without causing plastic deformations, allowing large recoverable strains to be achieved. These functional properties can be used to convert one type of energy such as magnetic or thermal energy into another-most frequently into mechanical energy. The main applications requiring SMA, which

Gregory Gerstein

gerstein@iw.uni-hannover.de

1 Institut Für Werkstoffkunde (Materials Science), Leibniz Universität Hannover, Garbsen, Germany provide a high degree of deformation during reversible conversion, are sensors and actuators. These undergo phase transformations in the temperature range of the martensitic transformations. The disadvantages preventing a widespread implementation of these alloys are: (1) a rapid functional degradation when using polycrystalline SMA and (2) insufficient initial stresses in the material, which would be required to easily activate the phase transformations.

Consequently, a comprehensive approach to overcome and eliminate both problems is necessary. Previous studies [1-5] suggest that a solution to the first problem can be achieved by a targeted dosed deformation of a distinct type. The second problem can be addressed by developing bi- or multicomponent actuators in which one component has a shape memory effect and the other features high elasticity. One approach to solve the second problem can be the development of a two- or multicomponent metallurgical joint of materials. Such a multicomponent material, however, can only be produced by applying a specific type of targeted strain to the material. This means that the approach to solve both main problems is to create distinct deformation processes for the respective materials.

Hot deformation (compression, rolling and extrusion) of SMA encased in steel plates [1] can increase the performance characteristics of the actuators by influencing 
their microstructure but also contribute to accumulation of different defects [1-5]. In particular, a high density of defects is observed after cold forming. Hot deformation of SMA in a shell can lead to significantly fewer microstructural defects, which in turn should improve the efficiency and long-term performance of an SMA actuator. During hot deformation it is important to take into account not only the geometry of the working element, but also the strain-stress behavior to obtain a low density of accumulated defects during forming, and thus improve the functional properties of the SMA. In this context, on key aspect is functional degradation upon cyclic loading. Accordingly, when evaluating the usability of an SMA, not only the initial working performance is important, but also its performance stability and the transformation temperatures stability as well as the evolution of the strains during thermal cycling [6]. In many cases functional degradation is mainly governed by the stability of the martensitic microstructures, and the presence of phases that affect the distribution of the internal stresses in the material [7]. As described in detail in [8], the martensite morphology determines the ability of a material to fully recover its shape.

Although controlling the strain-stress state during hot-forming operations promises to improve the quality of SMA-based products by influencing the mentioned characteristics, there is still a lack of suited hot forming operations. Hence, the possibility of macro-defect-free hot forming of SMAs, which are brittle at room temperature, is investigated in the following. Different technological processes are considered such as hot tensile tests, upsetting, rolling and extrusion. An outer massive steel shell is applied in all processes based on the assumption that this allows to increase the homogeneity of the deformation of the SMA-core and decrease its temperature losses. Another aspect of such a joint deformation of dissimilar materials is the possibility of a metallurgical bonding and the bonding quality. Here, the outer material, i.e. the shell material, can be used to act as an elastic bias component to promote a high metallurgical bonding quality.

\section{Experimental}

\subsection{Materials}

For the investigations, the high temperature SMA $\mathrm{Co}_{49} \mathrm{Ni}_{21} \mathrm{Ga}_{30}$ and the magnetic $\mathrm{SMA}$ $\mathrm{Ni}_{49.5} \mathrm{Fe}_{14.5} \mathrm{Mn}_{4.0} \mathrm{Ga}_{26.0} \mathrm{Co}_{6.0}$ were used as core materials and a ferritic medium carbon steel (1.0503) as employed as the shell material. In the following, the SMA are referred to as $\mathrm{CoNiGa}$ and $\mathrm{NiFeGa}$. Both SMA feature promising actuator characteristics. However, in the as-received polycrystalline state (Fig. 1) their functional characteristics cannot be fully exploited due to high intergranular stresses that arise upon phase transformations. Thus, improved characteristics in terms of functional stability are to be expected by hot forming, if grain orientation differences will be lowered due to hot forming, which in turn would reduce internal stresses.

\subsection{Hot compression tests}

Hot compression tests in the temperature range from 600 to $1000{ }^{\circ} \mathrm{C}$ were carried out to determine the flow stresses of the individual SMA by employing a universal tensilecompression machine (Walter + Bai $100 \mathrm{kN}$ ) equipped with an electric split tube furnace (EVT 1200) and a ceramic insulation of the compression plates. For these experiments, cylindrical samples with an initial diameter of $4 \mathrm{~mm}$ and a height of $6 \mathrm{~mm}$ were used. The tests were run in with constant strain rate of $0.001 \mathrm{~s}^{-1}$.

\subsection{Selection of hot forming processes}

To determine suitable load conditions and degrees of deformation for the hot forming of the SMA, different hot forming processes were evaluated, i.e. uniaxial tensile testing, upsetting, hot rolling and extrusion. The processes selected cover deformation states from pure tension to multiaxial compression. Figure 2 shows the stress and strain conditions present in the considered processes for a representative
Fig. 1 As-received microstructures of $\mathbf{a} \mathrm{CoNiGa}$ and $\mathbf{b}$ $\mathrm{NiFeGa}$ contrasted with Adler etchant
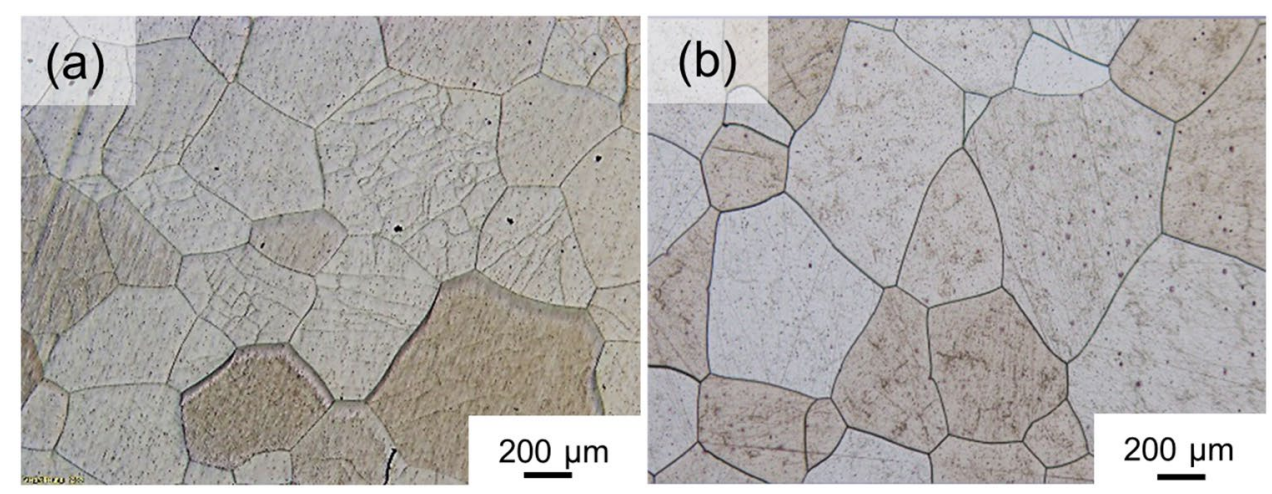



Fig. 2 Types of deformation processes applied and resulting orthogonal axial components of stresses and strains

volume element of the SMA within the samples' core. The lengths of the arrows qualitatively correspond to the stress and strain normal components in the respective directions. Shear stresses and strains are not shown in order to simplify the presentation. The first process is characterized by uniaxial tensile stresses; the further processes by multiaxial compression, wherein maximal level of hydrostatic stress is typical for extrusion.

Bar rolling and upsetting feature qualitatively similar strain and stress states. However, for bar rolling, the magnitudes of the stresses and strains along the $x$-axis differ significantly from those in the $y$-direction. In contrast, stresses and strains in $x$ and $y$ directions for the upsetting are equal. The third process featuring multiaxial compression is extrusion. Its key feature is a very high level of stresses and strains. Hence, the processes in Fig. 2 are characterised by an increasing level of the spherical component of stress tensor (hydrostatic pressure) from left to right and as a result increasing deformation energy that is introduced into the specimen. This in combination with the high forming temperatures was supposed to result in significant changes in the microstructures and the resulting properties.

\subsection{Sample geometries}

The sample geometries used for the tensile, upsetting, rolling und extrusion tests are shown in Fig. 3. The samples consisted of a shell of 1.0503 steel and a core of the SMA.
Welded pins of the steel 1.0503 were used to close the shell after inserting the SMA core.

In the following, the four forming operations will be described in detail.

\subsection{Hot tensile tests}

The hot tensile tests were carried out in a universal material testing system (MTS Landmark ${ }^{\mathrm{TM}} 100 \mathrm{kN}$ ), which was equipped with an inductor for heating the specimen. The tensile specimens consisted of the $3 \mathrm{~mm}$ SMA diameter core and the $10 \mathrm{~mm}$ diameter steel shell (Fig. 3a). The specimens were strained at $800{ }^{\circ} \mathrm{C}$ to $\varepsilon=10 \%$ and $\varepsilon=15 \%$ with a nominal strain rate of $0.001 \mathrm{~s}^{-1}$.

\subsection{Upsetting tests}

The upsetting tests were carried out in a universal testing machine (Zwick Roell Z250SN, $250 \mathrm{kN}$ ) at a constant cross head speed of $1 \mathrm{~mm} \mathrm{~s}^{-1}$. The tool set used consisted of a die and punch as depicted in Fig. 4. Prior to testing, the tool was heated to $500{ }^{\circ} \mathrm{C}$ and the specimen to $1000{ }^{\circ} \mathrm{C}$. The samples were composed of a SMA core with a diameter of $6 \mathrm{~mm}$ and a height of $10 \mathrm{~mm}$ and a steel shell as shown in Fig. 3b. The temperature of the shell surface dropped during transfer and installation into the tool. At the start of upsetting the temperature was in the range $740-760{ }^{\circ} \mathrm{C}$ decreasing to $630-650{ }^{\circ} \mathrm{C}$ at the end of processing. 
Fig. 3 Geometries to obtain samples for a tensile testing, $\mathbf{b}$ upsetting, $\mathbf{c}$ rolling and $\mathbf{d}$ extrusion (geometry of the extrusion billets is given in Table 1)

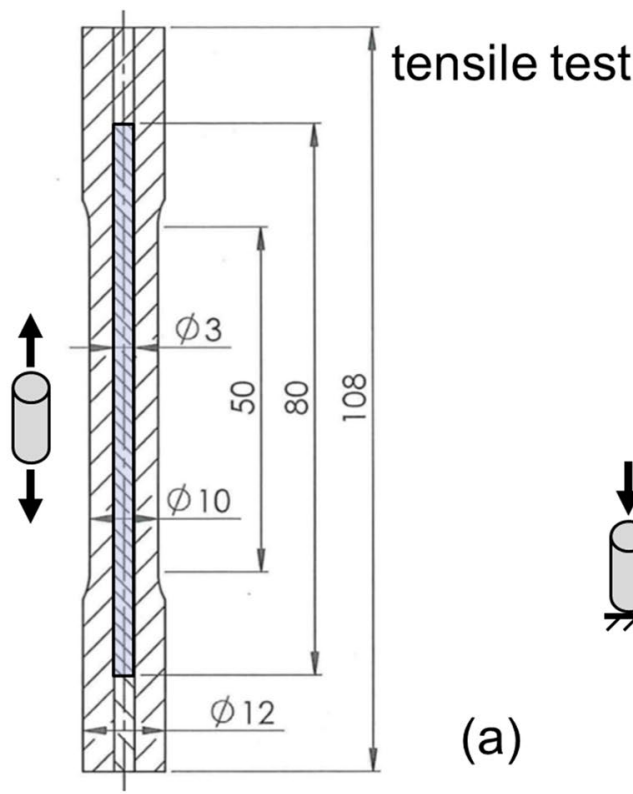

SMA core

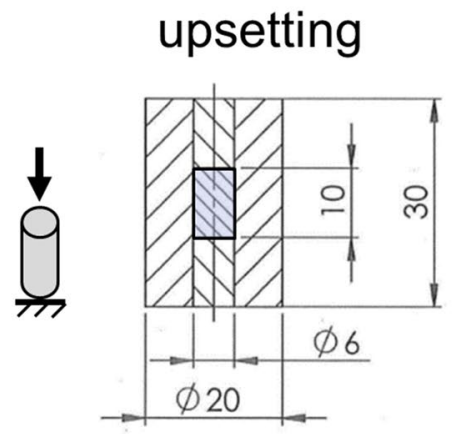

(b)

bar rolling
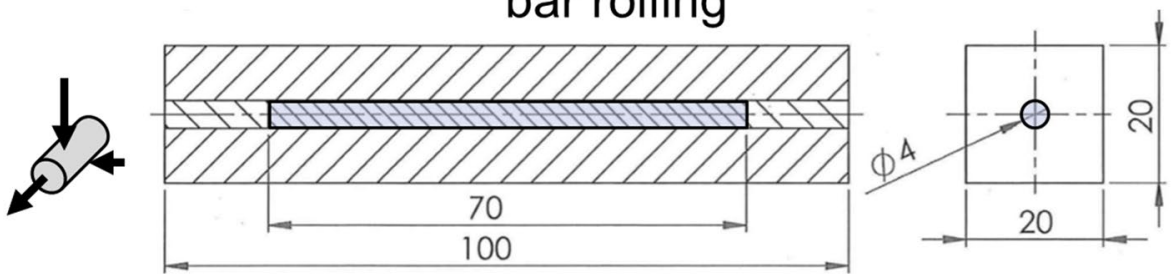

(c)

extrusion
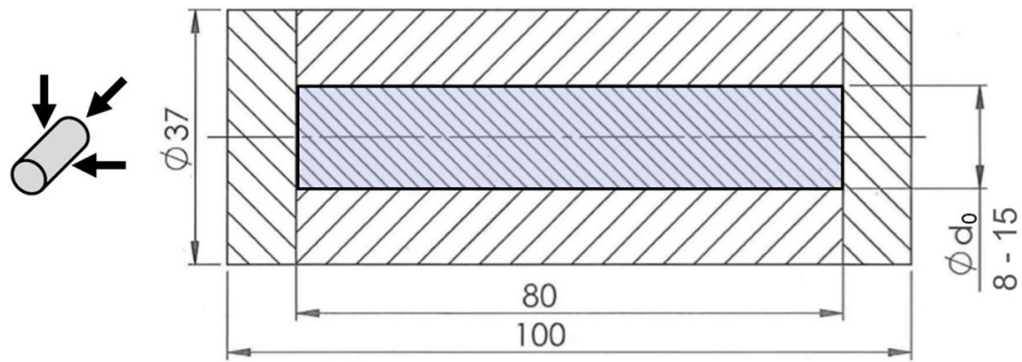

(d)

\subsection{Hot rolling}

Longitudinal hot rolling was carried out in a rolling mill (Bühler $200 \mathrm{kN}$ ), which was equipped with roll bandages (Fig. 5a). The caliber walls limit the material flow in the transverse direction, leading to an additional formation of compression stresses $[9,10]$, which prevents the formation of defects such as pores and cracks [11]. An oval caliber with a groove radius of $27.5 \mathrm{~mm}$ and nominal width of $32 \mathrm{~mm}$ was employed (Fig. 5b).

The billets consisted of square steel shell of $20 \mathrm{~mm} \times 20 \mathrm{~mm} \times 100 \mathrm{~mm}$ (Fig. 3c) and a cylindrical SMA core with a diameter of $4 \mathrm{~mm}$ and a length of $70 \mathrm{~mm}$. Prior to rolling, the samples were heated in a furnace to $1200^{\circ} \mathrm{C}$. For the first series of experiments, steel samples with SMA cores of $4 \mathrm{~mm}$ in diameter were used. The rolling was carried out in one pass.

In an additional set of experiments, the core consisted of two different SMAs in order to investigate if these could be bonded and the resulting bonding quality. Therefore, the two cores were shaped in form of two equal half-cylinders with the same radius, contacting with their flat longitudinal surfaces.

\subsection{Extrusion}

Extrusion was carried out with a $2.5 \mathrm{MN}$ extrusion press. The outer diameter of the container was $43 \mathrm{~mm}$, and the outer diameter of the billet $D_{0}$ was $37 \mathrm{~mm}$. The total length of the container was $100 \mathrm{~mm}$ and the length of the SMA 
Fig. 4 Tool set for a upsetting and $\mathbf{b}$ sample after the upsetting operation
Fig. 5 Hot bar rolling: a rolling mill used and $\mathbf{b}$ caliber form with initial billet geometry
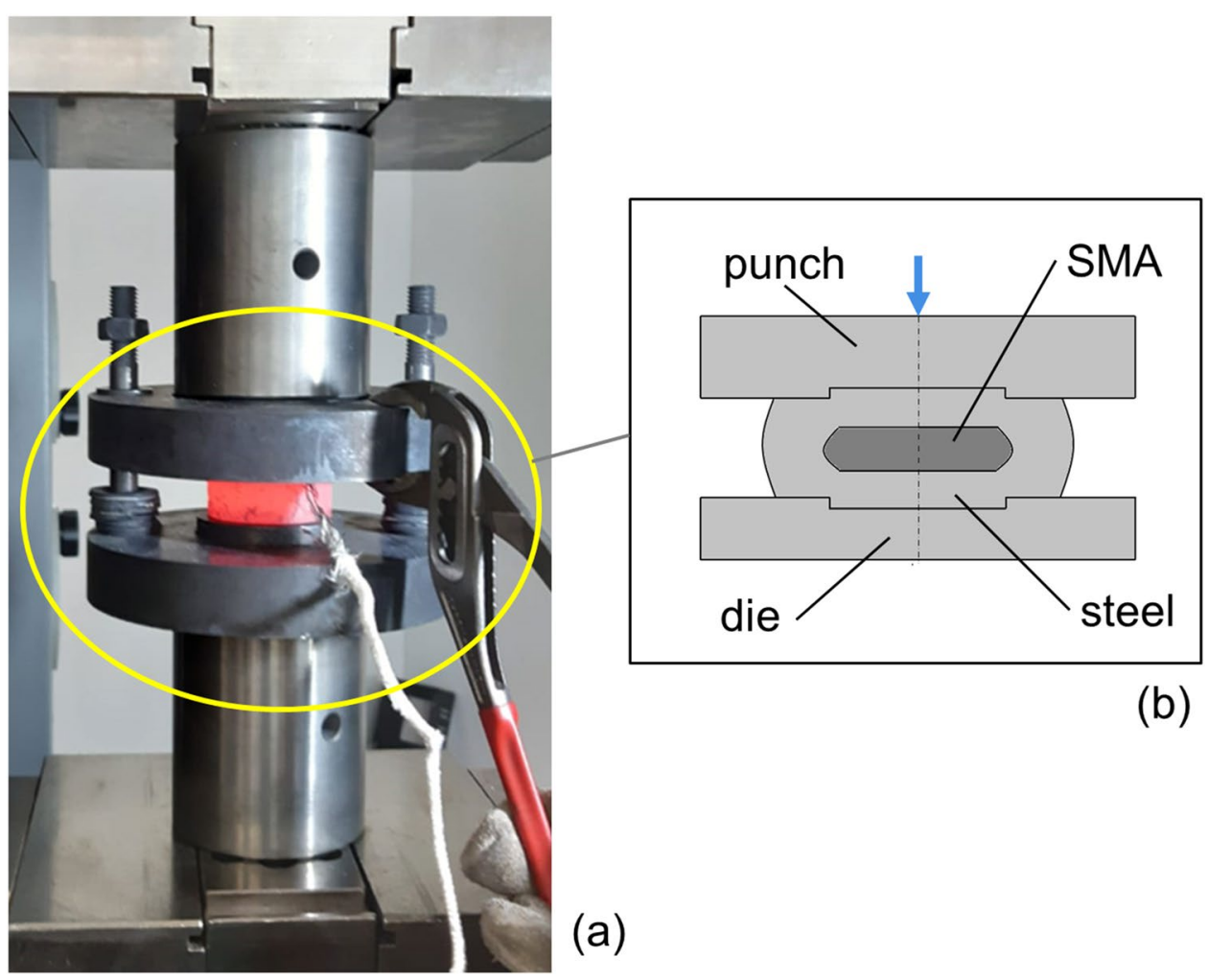

(b)

(a)
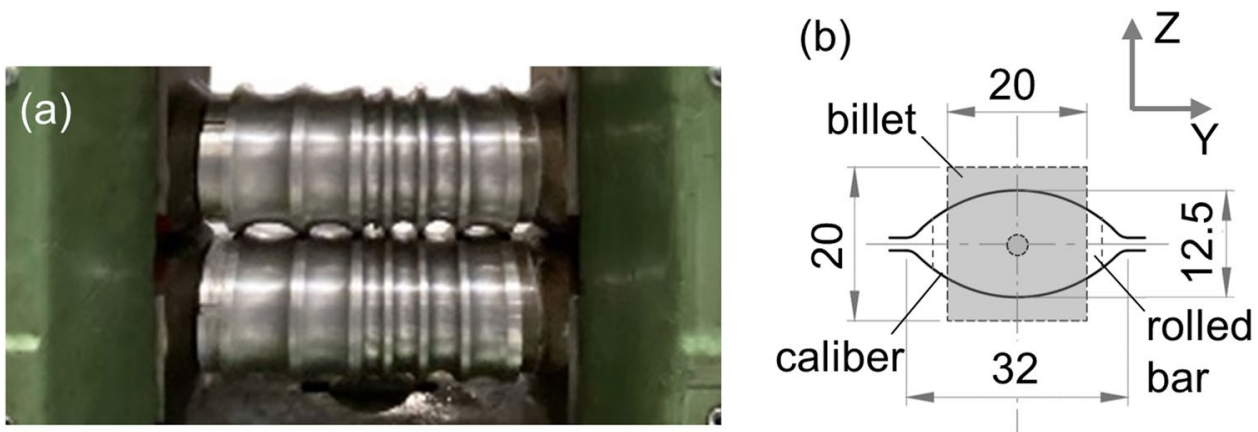

Table 1 Extrusion parameters

\begin{tabular}{lllll}
\hline Core material & \multicolumn{2}{l}{ CoNiGa } & & $\mathrm{NiFeGa}$ \\
\hline Initial diameter of core $d_{0}, \mathrm{~mm}$ & 8 & 12 & 15 & 4 \\
Die diameter $D_{\mathrm{d}}, \mathrm{mm}$ & 20 & & & 20 \\
Extrusion ratio $E R$ & $4.6: 1$ & & $4.6: 1$ \\
$\quad \begin{array}{l}\text { Real (logarithmical) deformation, } \\
\quad \ln (E R)\end{array}$ & 1.52 & & 1.52 \\
$\quad$ Ratio $d_{0} / D_{0}$ & 0.22 & 0.32 & 0.41 & 0.11 \\
\hline
\end{tabular}

inner core was $80 \mathrm{~mm}$ (Fig. 3d). The initial diameters $d_{0}$ of the inserted SMA cores were varied according to Table 1.

The billets with a core of $\mathrm{NiFeGa}$ or CoNiGa were extruded at extrusion ratio $(E R)$ of 4.6:1. The diameter of the CoNiGa core was varied from 8 to $15 \mathrm{~mm}$ to analyse the influence of the ratio $\mathrm{d}_{0} / \mathrm{D}_{0}$. The die diameter was chosen bigger than core diameters to prevent tool damage. The billets were heated to a temperature of $1200{ }^{\circ} \mathrm{C}$. The temperature of the tool (container, dummy block and the die) was $500{ }^{\circ} \mathrm{C}$. Before extrusion, the billet surfaces were coated with a glass powder as lubricant that melted due to the high temperature of the billet. The strain rate calculated according to [12] was obtained as $2.7 \mathrm{~s}^{-1}(E R=4.6: 1)$. Relatively high loading speeds at extrusion and rolling were necessary to minimize cooling of the specimens due to contact with the tools.

\subsubsection{Push-out-test}

Push-out-tests were employed to evaluate the bonding strength between the steel shell and the SMA core after 
extrusion. For these tests, $4 \mathrm{~mm}$ thick disk with a height of $4 \mathrm{~mm}$ were cut from the samples. The disks were then placed on a die with an orifice diameter $0.2 \mathrm{~mm}$ larger than the SMA core diameter. A punch tool with a diameter $0.2 \mathrm{~mm}$ smaller than the core diameter was pushed into the disk. The mean technical shear stress was calculated as the quotient of force to contact surface.

\section{Results}

\subsection{Hot compression tests and flow curves}

To determine suitable forming temperature for the SMA, flow curves in the temperature range from 600 to $1000{ }^{\circ} \mathrm{C}$ were measured. These temperatures were chosen to cover the range in which the ductile $\gamma$-phase is present for both SMA. Additionally, flow curves for the steel 1.0503 were extrapolated based on data from [13] since the shell was required to have a similar strength to strength of the core in this temperature range. The SMA flow curves from the hot compression tests and the extrapolated flow curves for the steel 1.0503 are depicted in Fig. 6.

In the temperature range of interest, the flow stresses are similar for both SMA and the steel 1.0503. The differences are smaller than $40 \mathrm{MPa}$ at lower testing temperatures and $25 \mathrm{MPa}$ at higher temperatures.

\subsection{Samples after forming}

The macroscopic appearance of the samples after the forming tests are shown in Fig. 7. The images are obtained from the CoNiGa-steel samples after the tensile, upsetting, rolling and extrusion tests. For the sake of brevity, the NiFeGa samples are not shown as these looked similar after forming.
Still, there were differences between the CoNiGa und $\mathrm{NiFeGa}$ samples as described in the following. The observed differences in the values of the degrees of deformation leading to damage in the structure of, respectively, CoNiGa and $\mathrm{NiFeGa}$ samples are given in the corresponding chapters and described in the following.

\subsubsection{Hot tensile tests}

Figure 7a and b show X-ray images (Zeiss Xradia 520 Versa) of the CoNiGa tensile samples strained to $10 \%$ and $15 \%$. The strain increase from $10 \%$ (Fig. 7a) to 15\% (Fig. 7b) resulted in the formation of cracks in the CoNiGa core. The cracks occur in those areas where a constriction in the steel shell is visible. These regions are either in the center of the sample or close to the grip section. In the NiFeGa samples, no macro cracks were observed at strains of $10 \%$ and $15 \%$, but numerous meso- and microcracks. Further in situ studies under load are under consideration for both alloys in order to analyze the different cracking mechanisms.

\subsubsection{Upsetting}

Figure $7 \mathrm{c}$ depicts the center-cut of an upsetting sample. The tests were interrupted when the maximal capacity of $230 \mathrm{kN}$ of the test system was reached. Height reduction of the whole sample was $41 \%$ for the CoNiGa-steel and $52 \%$ for the $\mathrm{NiFeGa-steel} \mathrm{samples.} \mathrm{The} \mathrm{compression} \mathrm{of} \mathrm{the} \mathrm{cores} \mathrm{was}$ $31 \%$ (CoNiGa) and $44 \%$ (NiFeGa). The lesser deformation of CoNiGa is probably due higher flow stresses of this alloy at temperatures above $700{ }^{\circ} \mathrm{C}$. The free outer surface of the deformed sample had a barrel form typical for upsetting. The angular form at the interface between core and shell is a result of contact friction with the tool due to centering undercuts.
Fig. 6 Measured flow curves of CoNiGa (solid lines), $\mathrm{NiFeGa}$ (dashed lines) and flow curves extrapolated based on data provided in [13] for the steel 1.0503 (dash-dot lines); experimental values for strains below 0.03 not depicted due to initial instability effects

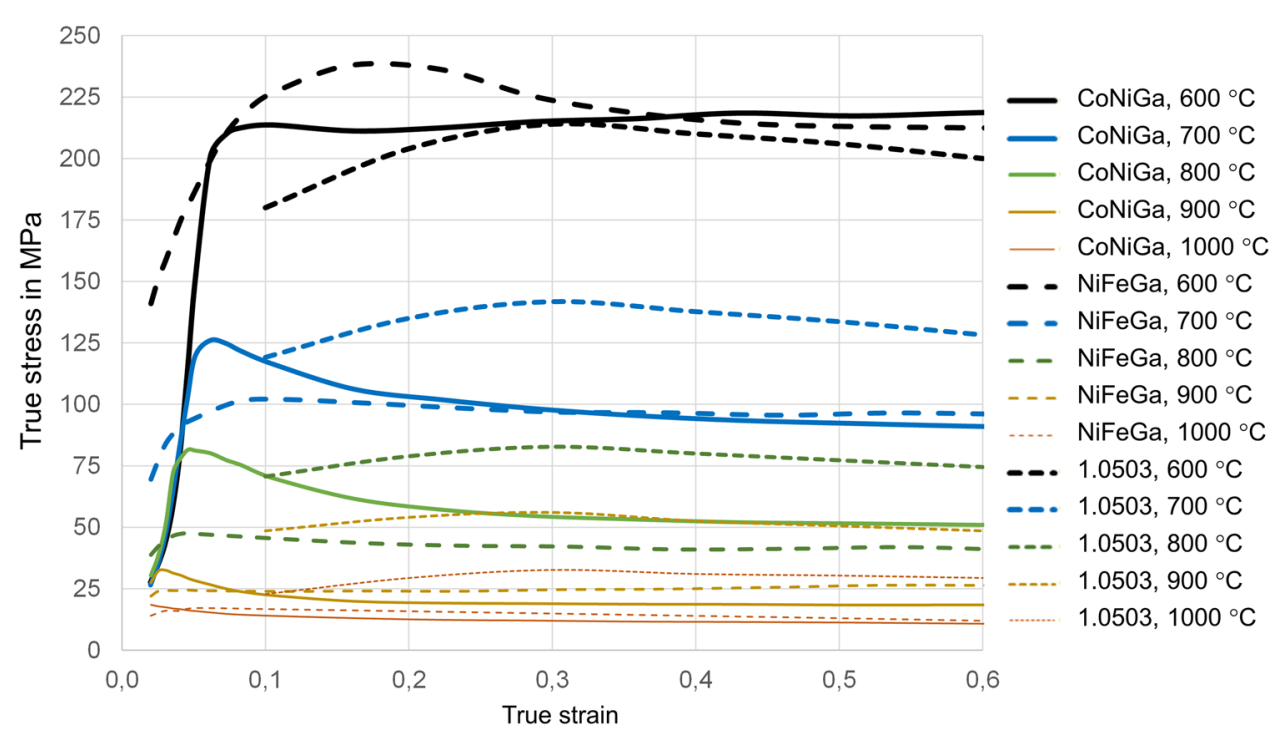


Fig. 7 Macroscopic appearance of the samples after forming (CoNiGa): a, b tensile test, $\mathbf{c}$ upsetting, $\mathbf{d}$ hot rolling and $\mathbf{e}$ extrusion; true strain: a 0.10 , b 0.14, c 0.53, d 0.50, e 1.23
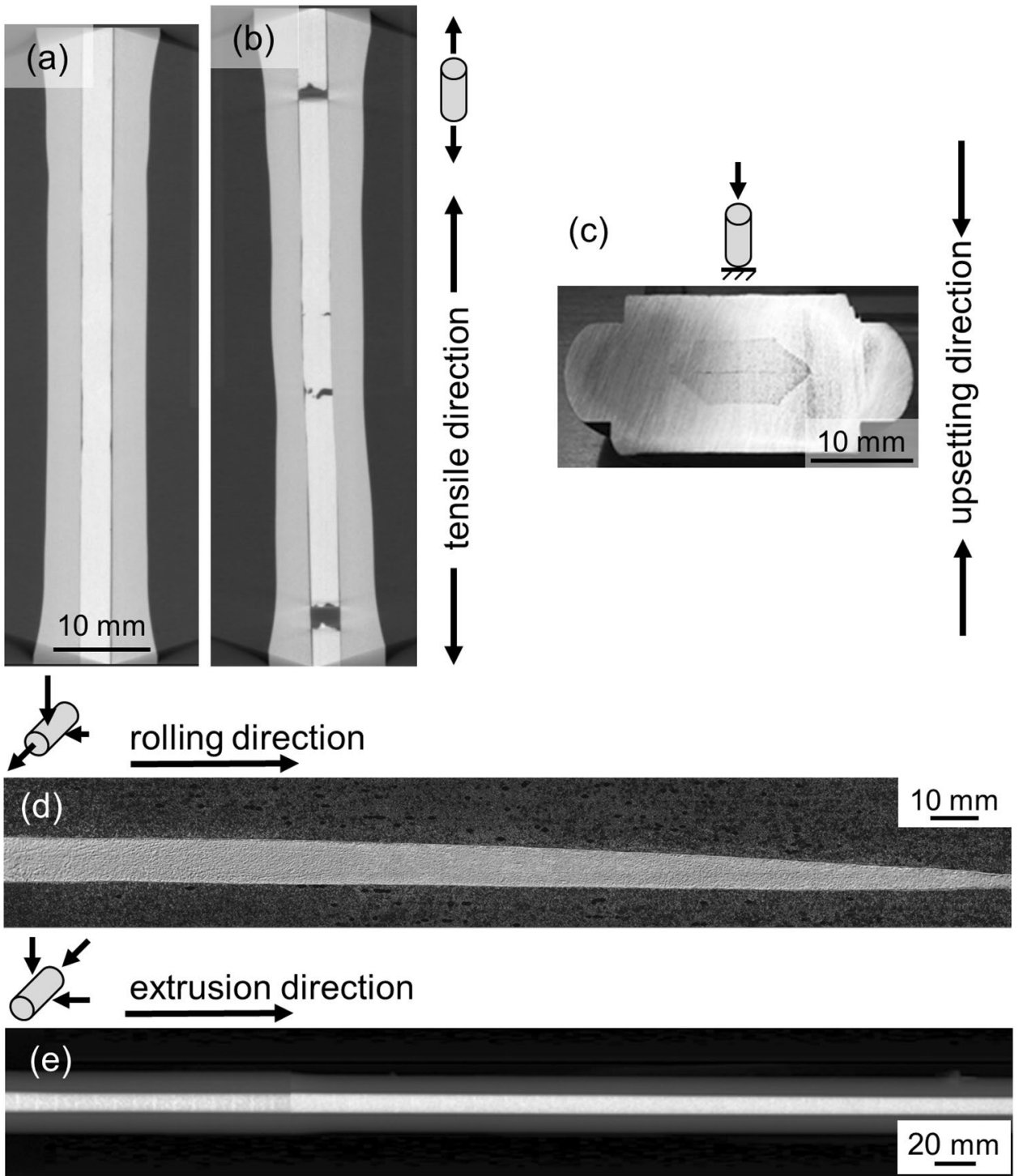

\subsubsection{Hot rolling}

Figure $7 \mathrm{~d}$ shows the longitudinal section of a hot rolled rod with a CoNiGa core. An elongation ratio $l_{1} / l_{0}$ of 1.53 was achieved. The final samples had a height of $12 \mathrm{~mm}$ and width of $27 \mathrm{~mm}$. Peripheral speed of the rolls was $50 \mathrm{~mm} \mathrm{~s}^{-1}$. Thus, the mean strain rate was $1 \mathrm{~s}^{-1}$. The surface temperature at the start, middle and end of the sample measured with a HT3305 pyrometer was in the range of $930-970{ }^{\circ} \mathrm{C}$. The mean value of the rolling pressure was $76 \mathrm{MPa}$. The NiFeGa samples were nearly identical in appearance and shape to the CoNiGa samples shown in Fig. 7d.

\subsubsection{Extrusion}

After processing, the main part of the extruded rod remains in the extrusion tool until manually removed and it is challenging to measure its temperatures with a pyrometer. The surface color of the rods right after extrusion was bright red to red, but it is difficult to estimate the corresponding temperature due to the lubricant glass layer. However, the temperature was not below $800{ }^{\circ} \mathrm{C}$. In comparison to the other forming methods, the highest degrees of deformation were achieved during extrusion. From the X-ray image of an extruded rod (Fig. 7e), the shape of the formed core could be evaluated non-destructively. In Fig. 7e, a homogenous deformed CoNiGa core in the steel shell is visible. Such homogenous elongation was obtained for all ratio combinations of $d_{0} / D_{0}$. Despite the different extrusion parameters, the appearance of the NiFeGa samples after extrusion was similar to the CoNiGa samples shown in Fig. 7e. 


\subsection{Characterization of the interface zone between core and SMA shell}

Regarding the subsequent separation of the SMA core and the steel shell, the interface between both materials after forming is of interest. Accordingly, backscattered electron images were recorded in a scanning electron microscop (SEM) of the interfaces formed in the CoNiGa-steel and $\mathrm{NiFeGa-steel} \mathrm{samples.} \mathrm{Table} 2$ shows representative SEM images of the interfaces between the shell and the core.

The analysis of the interfaces formed between the core and the shell materials revealed that distinction in types and degrees of deformation determine a difference in bonding quality. As seen from Fig. 7a, b and c and Table 2a-d, the use of hot tensile testing and upsetting does not promote formation of a metallurgical joint between the investigated materials. The core and shell materials could easily be separated after cutting the final products. Bar rolling with the parameters employed resulted in a strong material bond between the SMA and the steel shell (Table 2e, f). The most intensive metallurgical bond was formed for specific sets of extrusion parameters (Table $2 \mathrm{~g}$, h). The interface between the CoNiGa core and the steel shell are shown in Fig. 8 for selected of extrusion conditions. A positive influence of increasing the diameters ratio $d_{0} / D_{0}$ regarding formation of a strong bonding during extrusion was determined. For a ratio of $d_{0} / D_{0}=0.22$, large voids between the SMA and the steel shell were present (Fig. 8a). By increasing the ratio to 0.32 , the voids decrease in size (Fig. 8b) and at some points, a material bond can be assumed. Increasing the ratio to 0.41 causes a full material bond (Fig. 8c).

The results for extruding NiFeGa with a ratio $d_{0} / D_{0}=0.11$ are depicted in Fig. 9. Despite the substantially lower ratio, a firm bond between the $\mathrm{NiFeGa}$ and the steel shell was obtained.

Additional line scans were taken to characterize the interface zone. Figures 10 and 11 show the line scans for CoNiGa and NiFeGa cores for $d_{0} / D_{0}=0.41(\mathrm{CoNiGa})$ and

Table 2 Interfaces formed between steel shell and SMA core resulting from the different forming processes and conditions (steel at the bottom part of the pictures; SMA at the top)

\begin{tabular}{|c|c|c|c|}
\hline Process & CoNiGa-steel & NiFeGa-steel & Bonding situation \\
\hline Hot tensile test & & & $\begin{array}{l}\text { Few contact points demonstrating a material } \\
\text { bond }\end{array}$ \\
\hline Upsetting & (c) & (d) & Some sections featuring a material bond \\
\hline Hot rolling & (e) & (f) & $\begin{array}{l}\text { Full material bonding for the processing } \\
\text { parameters employed }\end{array}$ \\
\hline Extrusion & $(9$ & (h) & $\begin{array}{l}\text { Full material bonding, but only for certain } \\
\text { processing parameters }\end{array}$ \\
\hline
\end{tabular}



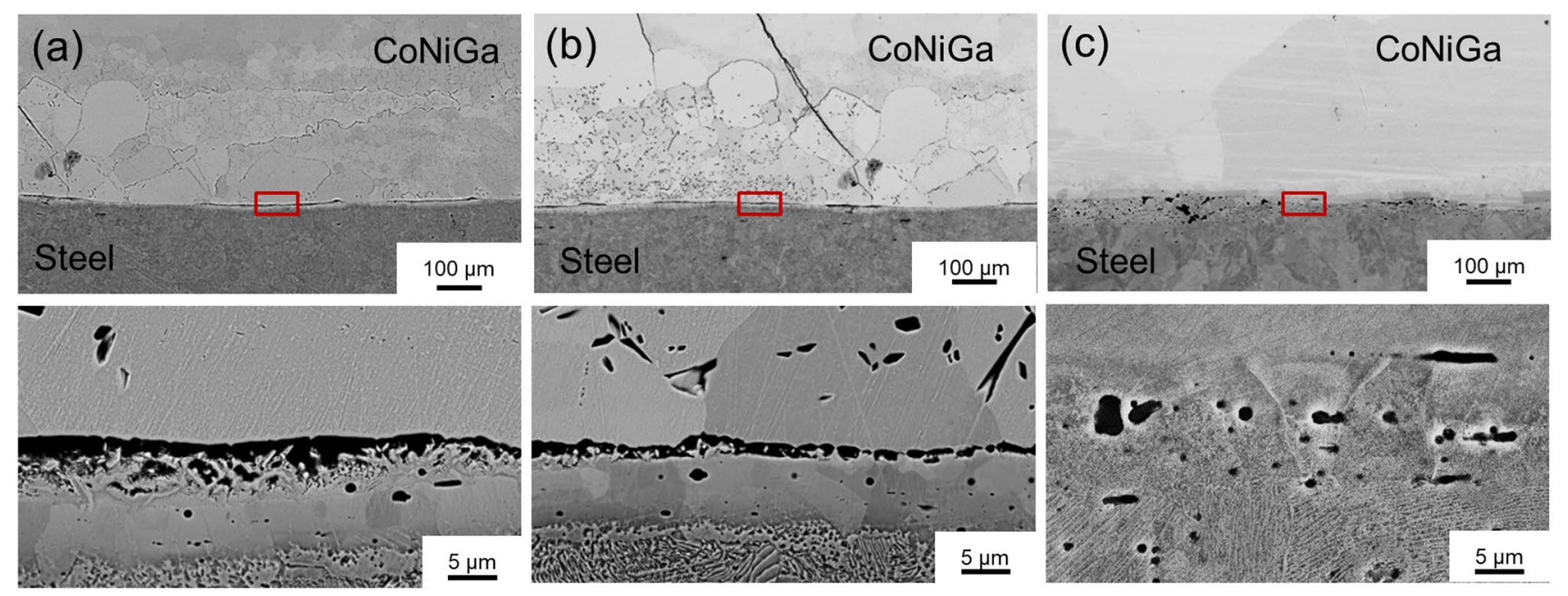

Fig. 8 SEM images (BSD) of the bonding zone in longitudinal sections of CoNiGa rods with a ratio of a $d_{0} / D_{0}=0.22, \mathbf{b} d_{0} / D_{0}=0.32$ and $\mathbf{c}$ $d_{0} / D_{0}=0.41$ for two magnifications (bottom row shows high magnification details of the areas marked in red)

Fig. 9 SEM images (BSD) of the bonding zone in longitudinal section of a NiFeGa rod with $d_{0} / D_{0}=0.11$; image (b) is a high magnification detail of the area marked in red in (a)
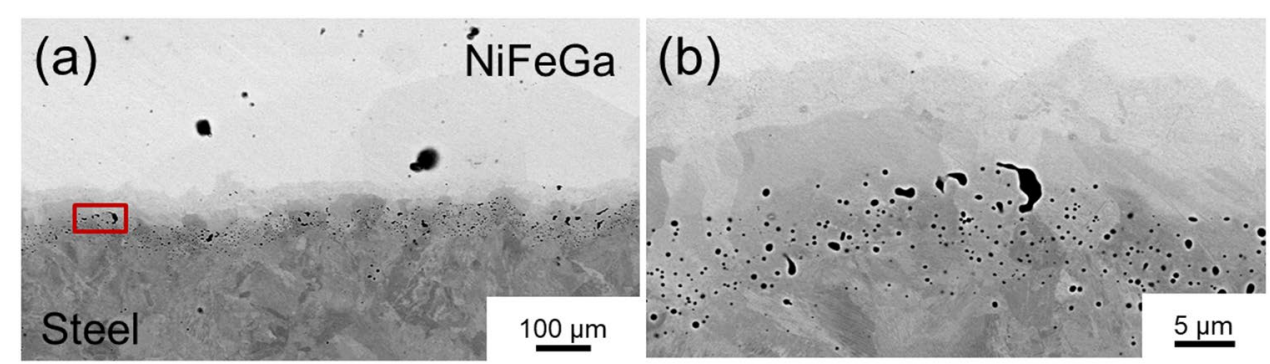

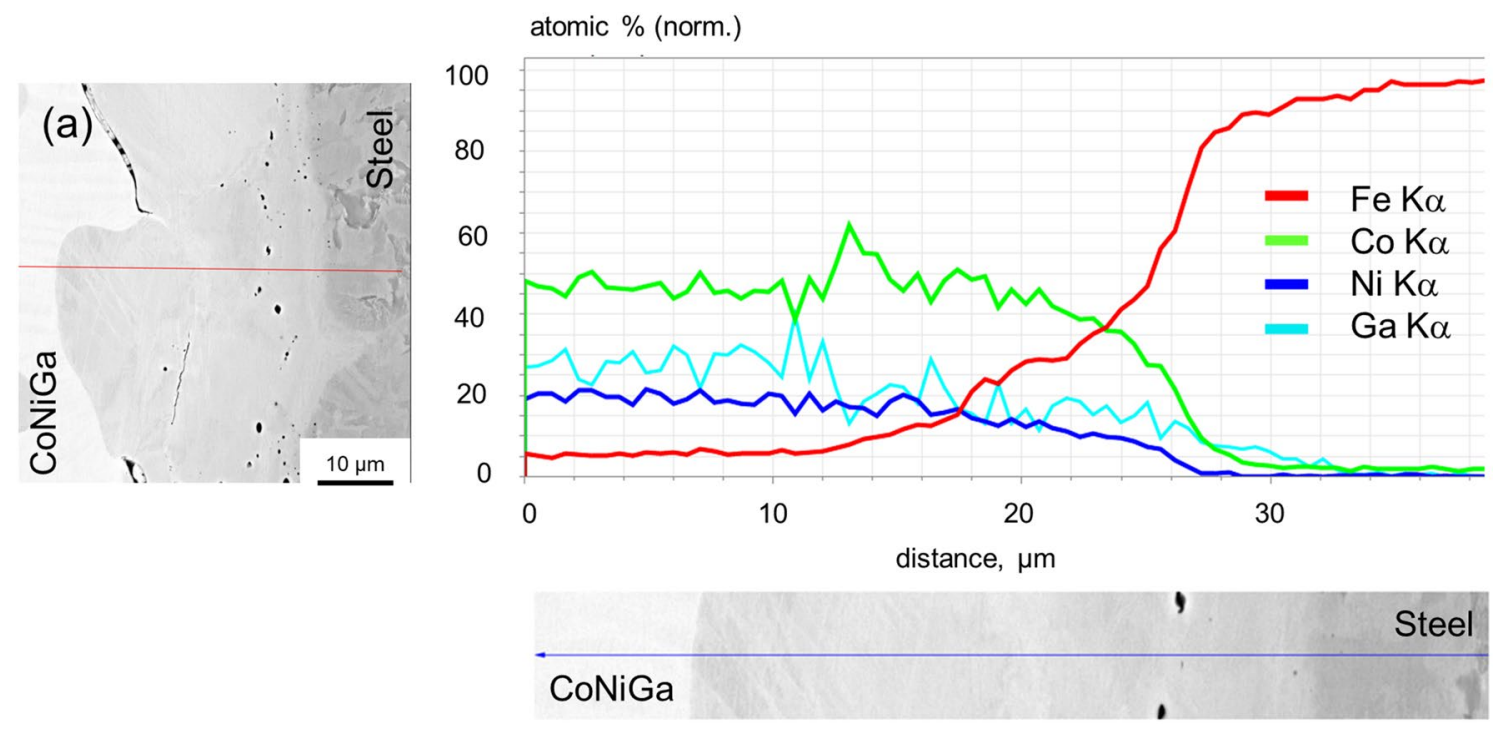

Fig. 10 EDX line scan analysis of the joining zone of CoNiGa and steel: a SEM image (BSD) with trace marked by a red line and $\mathbf{b}$ corresponding line profiles 




Fig. 11 EDX line scan analysis of the joining zone of NiFeGa and steel: a SEM image (BSD) with trace marked by a red line and b corresponding line profiles

$d_{0} / D_{0}=0.11(\mathrm{NiFeGa})$, respectively. The continuous character of the element concentration change in the line scans from the interface zone (Figs. 10b, 11b) indicates a firm material bond.

The porosity at the interface in all cases using a steel shell (Figs. 8, 9, 10,11) can be a consequence of the Kirkendall effect (condensation and growth mechanism of voids) and its cause is the difference in the diffusion rates of the carbon atoms present in steel and other elements composing the given alloys (Co, Ni, Ga, Fe). This assumption is supported by the absence of porosity at the interface between the two
SMA (Fig. 12). Static diffusion tests to clarify the role of carbon atoms and vacancies in pore formation are thus of further interest.

\subsubsection{Push-out tests}

To interpret the SEM images and the EDX line scan data, push-out tests were carried out to characterize the mechanical properties of the bond. The tests were performed for the different ratios of the extruded CoNiGa samples, and the results of the push-out tests are summarized in Table 3. The
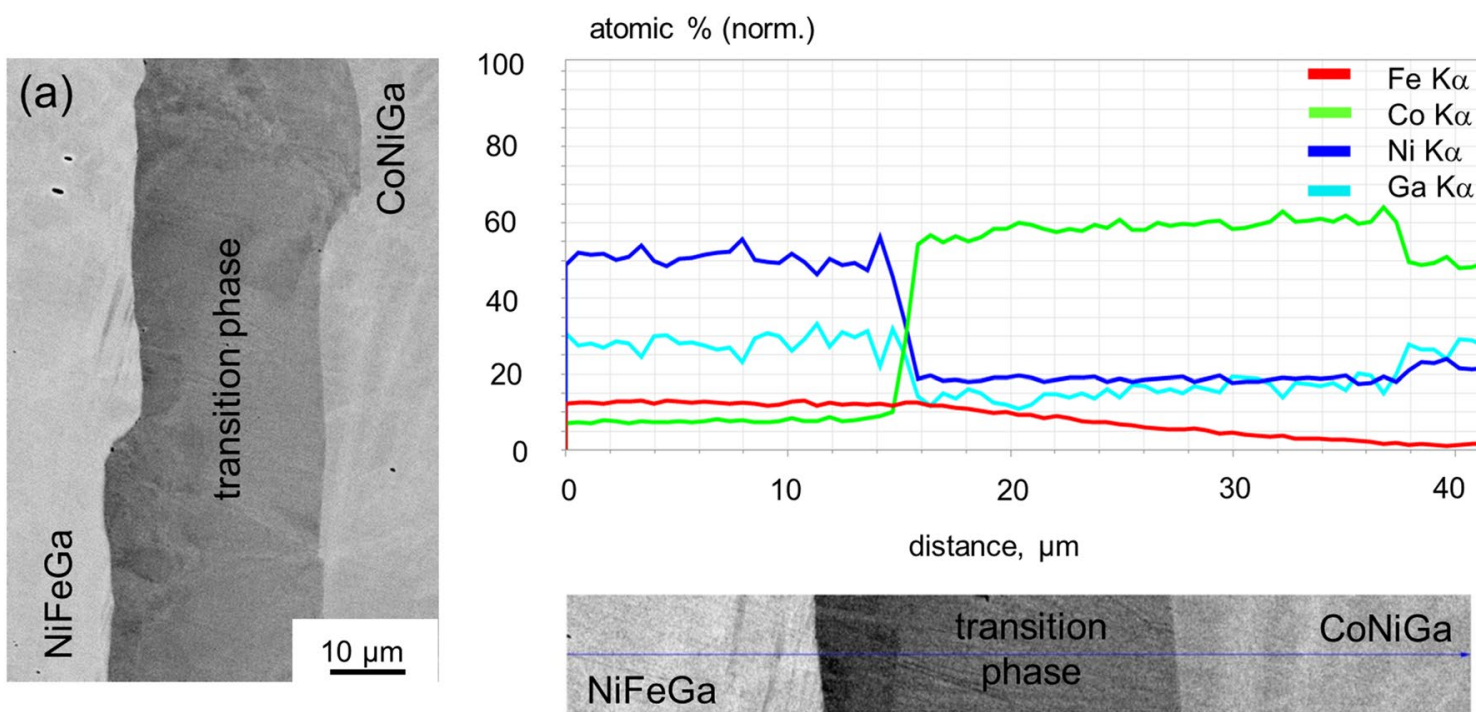

Fig. $12 \mathrm{CoNiGa} / \mathrm{NiFeGa}$ interface after hot rolling in a steel shell, longitudinal section: a SEM image (BSD) of microstructure and b EDX line scan 
Table 3 Influence of extrusion parameters on the shear strength $\tau_{\mathrm{c}}$ of the CoNiGa-steel bond as determined by push-out-tests

\begin{tabular}{lll}
\hline$d_{0} / D_{0}$ & $E R$ & $\tau_{\mathrm{c}}, \mathrm{MPa}$ \\
\hline 0.41 & 4.6 & 460 \\
0.32 & 4.6 & 204 \\
0.22 & 4.6 & 177 \\
\hline
\end{tabular}

shear stresses $\tau_{\mathrm{c}}$ are quite high compared to the samples taken from tensile test specimens, where a direct separation of parts of the sample was observed after preparation. In fact, the highest achieved bonding strength is close to the nominal strength of steel employed for the shell. This can be explained by two effects. The first one is a material bonding at interface between core and shell, and adhesion spots with remains of the steel shell were visible on the surface of the pushed-out cores. The second effect is a higher thermal expansion coefficient of steel compared to the SMA core leading to a shrink fit.

Increasing the ratios $d_{0} / D_{0}$ for a constant extrusion ratio $E R$ led to an increase in the bond strength. The bond strength at $d_{0} / D_{0}=0.41$ is about two times higher compared to tests on samples with $d_{0} / D_{0}$ of 0.22 and 0.32 . This confirms the metallographic data showing that increasing ratios of $d_{0} / D_{0}$ lead to a firm material bonding with a distinct transition zone.

\subsubsection{Hot bar rolling of SMA compounds}

As joining of the SMA and the steel shell by hot bar rolling was successful, an investigation of the potential to join two different SMA by bar rolling for the manufacturing of SMA compounds was undertaken. In these experiments two half cylinders made of $\mathrm{CoNiGa}$ and $\mathrm{NiFeGa}$ were placed in a steel shell that was subsequently hot bar rolled using the process parameters that were employed for the single SMA cores. An SEM image and a line scan of the joining zone between the two SMA after bar rolling are shown in Fig. 12. A bonding between the two materials was successfully achieved and a transition zone of about $25 \mu \mathrm{m}$ is visible in Fig. 12a. The chemical composition in this cobalt-rich transition phase (Fig. 12b) demonstrates a distinct stoichiometric ratio. In this regard, we can assume the possibility of a change in the stoichiometric ratio of the alloy composition. Unlike to the combination of SMA and steel, no Kirkendall pores occurred in the transition phase indicating a more balanced diffusion process in the absence of carbon in the atomic lattice.

In the optical image of Fig. 13, this phase appears light brown-grey and was identified as the $\gamma$-phase $[3,14]$ with a chemical composition of $\mathrm{Ni}_{48.6} \mathrm{Fe}_{17.1} \mathrm{Mn}_{4.1} \mathrm{Ga}_{23.7} \mathrm{Co}_{6.5}$. It has been observed that the formation of this transition $\gamma$-phase layer at the interface between core and shell depends on the local deformation conditions.

As can be seen from Fig. 13, the volume fraction of the $\gamma$-phase in the core increases with increasing degree of deformation of the material (from left to right in the figure). This means that besides a heat treatment one of the possible mechanisms for regulating the amount and nature of the $\gamma$-phase distribution can be the degree of plastic deformation as well.

\section{Discussion}

Using a thick-walled steel shell in combination with high process temperatures allowed the defect-free hot forming of the investigated $\mathrm{CoNiGa}$ and $\mathrm{NiFeGa}$ shape memory alloys. The average elongations of the contact lines achieved for the compression forming methods employed were 1.45 for upsetting, 1.53 for rolling and 3.42 for extrusion, respectively. The processes with the highest potential regarding a high degree of plastic deformation are rolling and extrusion. A similar result [15] was previously obtained for other NiTi-SMA only by a very costly explosion welding. It has already been shown that deformation according to [16] can influence SMA properties. A comparison of the different forming processes reveals that increasing strain values and temperatures have

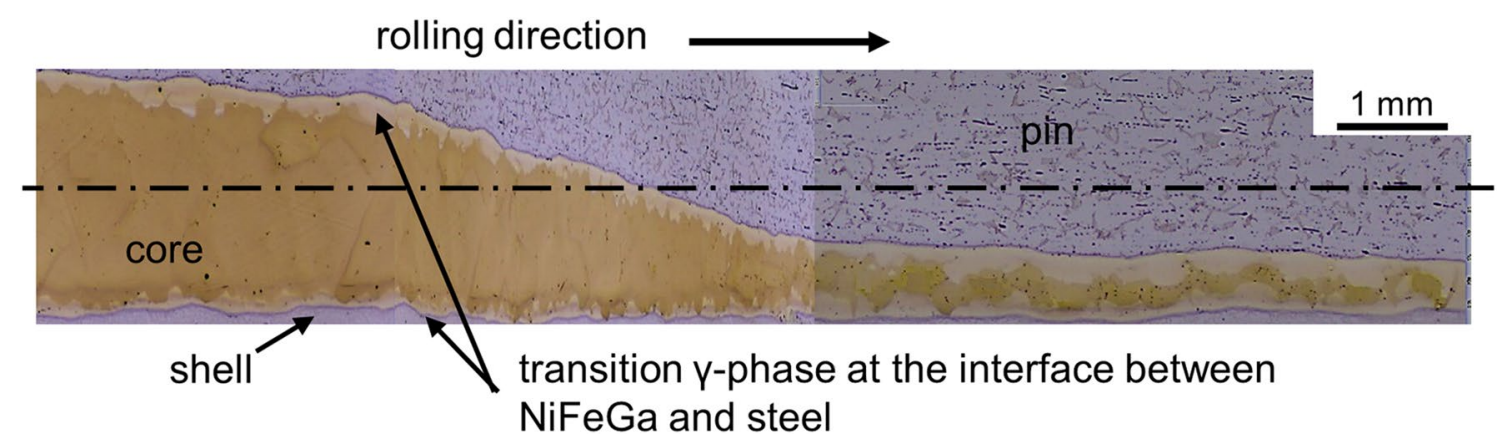

Fig. $13 \gamma$-phase (light brown-grey) in a longitudinal section of a NiFeGa core-steel shell after hot rolling etched with Adler's reagent 
a positive impact on the bondability of the core and shell, whereas elevated stresses and reduced strain rates are less significant. For example, for similar strain-stress states when rolling or upsetting but differing absolute stress levels-lower for rolling than for upsetting-sufficient juvenile surfaces at the contact zone form during rolling that promote a strong bonding. The bond quality of the extruded rods was higher than for the rolled rods. One possible explanation of this feature is the extended processing time: the material was under high hydrostatic pressure for several seconds during extrusion while this was only the case for about $0.5 \mathrm{~s}$ during hot rolling. Therefore, not only strain rates should be considered in future works but absolute processing times as well. This fact can be caused by the processes, which are similar to the processes giving rise to the well-known phenomenon of martensite aging. Hence, analysis of complete loading histories, e.g. strain-stress-time-temperature parameters should be considered for further optimizations, accompanied by e.g. FEM simulations.

One objective of the presented research was to investigate the interface between the SMA core and the steel shell regarding the subsequent separation of core and shell. It was found that the quality of the bond differs when applying different types of deformation. At upsetting and tension, the bonding between SMA core and steel shell is poor and it is quite easy to extract the deformed SMA cores from the shell. In the case of rolling and extrusion, it is very difficult to separate the core and the shell and for some processing parameters (Table 2e-h) a full material bond was achieved.

The growing bond strength with increasing core diameters or ratios $d_{0} / D_{0}$, which is given in Table 3 , can be explained by two effects. The first effect are increasing shear stresses and deformations; the closer a considered point (i.e. point on the shell-core contact) to the container surface, the higher the shear stress due to friction at its surface. The second effect is an unintentional cooling of metal volumes that are closer to the container surface, which results in increasing flow stresses. Such effects are described for monomaterials e.g. in $[12,17]$.

In addition, the analysis of the influence of the degree of deformation on the material bonding revealed the occurrence of a transition $\gamma$-phase in the NiFeGa-steel samples (Fig. 13). Since the presence of a phase with increased plasticity compared to the matrix has a substantial influence on the martensitic transformation and the functional properties of the SMA [14], the formation of the $\gamma$-phase at the interface, on the SMA grain boundaries and its distribution patterns in the volume are of great interest. The analysis of the deformation behavior of the $\gamma$-phase along the grain boundaries will be the subject of future research. The observed increase in the volume fraction of the $\gamma$-phase with the degree of deformation can be exploited to control the stress level arising at the martensite transformation front. This in turn will affect the temperature interval of the martensitic transformation and the degree of deformation reversibility.

\section{Conclusion and outlook}

1. The application of a thick-walled steel shell allows a successful hot forming of SMA cores without macro defects upon upsetting, rolling and extrusion.

2. For the different methods of metal forming employed, the most promising results regarding a high bonding quality were obtained for the extruded specimens, a lesser but still high bonding quality was observed for the roll bonding.

3. The ratio of the core diameter to the shell diameter during extrusion has a significant impact on the strength of the SMA-steel bond.

4. An important advantage of rolling in contrast to extrusion is the lesser temperature loss of the specimens during the processing due to the comparatively short contact times with the forming rolls. By contrast, extrusion allows for high degrees of deformation in combination with a significant increased contact time under high hydrostatical pressures.

5. High-temperature rolling of two SMA with differing mechanical properties revealed an excellent quality of the metallurgical bonding featuring a defect-free interphase transition zone.

The high bond qualities between the SMA cores and the steel shells as well as between the two SMAs achieved by extrusion and rolling offer the potential to use these compounds in future applications as thermomechanical hybrid actuators. Future analysis regarding the influence of hot deformation on the microstructural, mechanical and functional properties will provide an opportunity for a targeted optimization with a focus on actuator applications.

Acknowledgements Financial support by Deutsche Forschungsgemeinschaft (German Research Foundation) under project no. 252662854 is gratefully acknowledged. The authors also thank Dr. M. Rodman for help with the experiments. The Xradia 520 Versa used for the $\mathrm{x}$-ray imaging was also funded by the DFG (Project No. 316923185).

Funding Open Access funding enabled and organized by Projekt DEAL.

Open Access This article is licensed under a Creative Commons Attribution 4.0 International License, which permits use, sharing, adaptation, distribution and reproduction in any medium or format, as long as you give appropriate credit to the original author(s) and the source, provide a link to the Creative Commons licence, and indicate if changes were made. The images or other third party material in this article are 
included in the article's Creative Commons licence, unless indicated otherwise in a credit line to the material. If material is not included in the article's Creative Commons licence and your intended use is not permitted by statutory regulation or exceeds the permitted use, you will need to obtain permission directly from the copyright holder. To view a copy of this licence, visit http://creativecommons.org/licenses/by/4.0/.

\section{References}

1. Böhm A, Roth S, Naumann G, Drossel W-G, Neugebauer $R$ (2008) Analysis of structural and functional properties of Ni50Mn30Ga20 after plastic deformation. Mater Sci Eng A 481-482:266-270. https://doi.org/10.1016/j.msea.2007.01.193

2. Dogan E, Karaman I, Chumlyakov YI, Luo ZP (2011) Microstructure and martensitic transformation characteristics of $\mathrm{CoNiGa}$ high temperature shape memory alloys. Acta Mater 59(3):11681183. https://doi.org/10.1016/j.actamat.2010.10.050

3. Niendorf T, Lauhoff C, Karsten E, Gerstein G, Liehr A, Krooß P, Maier HJ (2019) Direct microstructure design by hot extrusion - high-temperature shape memory alloys with bamboo-like microstructure. Scr Mater 162:127-131. https://doi.org/10.1016/j. scriptamat.2018.10.051

4. Chulist R, Böhm A, Lippmann T, Skrotzki W, Drossel WG, Neugebauer R (2009) Twinning behaviour of textured polycrystalline Ni-Mn-Ga alloy after hot extrusion. Mater Sci Forum 635:195199. https://doi.org/10.4028/www.scientific.net/MSF.635.195

5. Karsten E, Gerstein G, Golovko O, Dalinger A, Lauhoff C, Krooss P, Niendorf T, Samsonenko A, Maier HJ (2019) Tailoring the microstructure in polycrystalline $\mathrm{Co}-\mathrm{Ni}-\mathrm{Ga}$ high-temperature shape memory alloys by hot extrusion. Shape Mem Superelasticity 5(1):84-94. https://doi.org/10.1007/s40830-019-00208-7

6. Sibirev A, Belyaev S, Resnina N, Nikolaev V, Timashov R, Averkin A (2020) Shape memory effects and work output of [001] Ni55Fe18Ga27 single crystals in torsion mode. J Mater Eng Perform 29(4):2185-2189. https://doi.org/10.1007/s11665-02004776-Z

7. L'vov VA, Kosogor A, Palamarchuk SI, Gerstein G, Maier HJ (2020) Influence of incorporated nanoparticles on superelastic behavior of shape memory alloys. Mater Sci Eng A 776:139025. https://doi.org/10.1016/j.msea.2020.139025
8. Maki T (1991) Microstructure and mechanical behaviour of ferrous martensite. Mater Sci Forum 56-58:157-168. https://doi. org/10.4028/www.scientific.net/MSF.56-58.157

9. Vater M, Schütza A (1972) Untersuchungen über den Formänderungsverlauf beim Warmwalzen von Stahl in einfachen Streckkalibern in Abhängigkeit von der Kaliberform und den Abmessungsverhältnissen. [in German]. Wiesbaden: VS Verlag für Sozialwissenschaften. Forschungsberichte des Landes NordheinWestfalen. 2247. ISBN 978-3-322-88346-9

10. Grudev AP, Maschkin LF, Khanin MI (1994) Technology of rolling production. Moscow, Publisher, Art-Business-Centre, Metallurgy (in Russian)

11. Imran M, Afzal MJ, Buhl J, Bambach M, Dunlap A, Schwedt A, Aretz A, Wang S, Lohmar J, Hirt G (2020) Evaluation of processinduced damage based on dynamic recrystallization during hot caliber rolling. Prod Eng 14(1):5-16. https://doi.org/10.1007/ s11740-019-00932-0

12. Bauser M, Sauer G, Siegert K (2001) Extrusion. Aluminium Verlag, Düsseldorf, (in German)

13. Polukhin PI, Gun GYa, Galkin AM (1983) Flow stress of alloys and metals. Moscow, Metallurgy (in Russian)

14. Panchenko EYu, Timofeeva EE, Chumlyakov YuI, Osipovich KS, Tagiltsev AI, Gerstein G, Maier HJ (2019) Compressive shape memory actuation response of stress-induced martensite aged $\mathrm{Ni}_{51} \mathrm{Fe}_{18} \mathrm{Ga}_{27} \mathrm{Co}_{4}$ single crystals. Mater Sci Eng A 746:448-455. https://doi.org/10.1016/j.msea.2019.01.004

15. Belyaev S, Evard M, Lomakin I, Resnina N, Rubanik V, Volkov A (2015) Functional properties of shape memory bimetal plate. Mater Today Proc 2:S723-S726. https://doi.org/10.1016/j.matpr .2015.07.384

16. Kustov S, Pons J, Cesari E, van Humbeeck J (2004) Chemical and mechanical stabilization of martensite. Acta Mater 52(15):45474559. https://doi.org/10.1016/j.actamat.2004.06.012

17. Perlin IL, Reitbart LKh (1975) Theory of extrusion of metals. Moscow, Metallurgy (in Russian)

Publisher's Note Springer Nature remains neutral with regard to jurisdictional claims in published maps and institutional affiliations. 